\title{
Pulmonary Lymphangitic Spread of Multiple Myeloma as Early Relapse after Autologous Stem Cell Transplantation
}

\author{
Bicky Thapa $\mathbb{D}^{1},{ }^{1}$ Gulrayz Ahmed $\left(\mathbb{D},{ }^{1}\right.$ Meera Mohan $\left(\mathbb{D},{ }^{1}\right.$ Volodymyr Shponka ${ }^{(D)}{ }^{2}$ \\ and Parameswaran Hari ${ }^{1}$ \\ ${ }^{1}$ Division of Hematology and Oncology, Department of Medicine, Medical College of Wisconsin, Milwaukee, WI, USA \\ ${ }^{2}$ Division of Pathology and Laboratory Medicine, Department of Medicine, Medical College of Wisconsin, Milwaukee, WI, USA
}

Correspondence should be addressed to Gulrayz Ahmed; gahmed@mcw.edu

Received 3 March 2021; Revised 23 March 2021; Accepted 26 March 2021; Published 5 April 2021

Academic Editor: Pier Paolo Piccaluga

Copyright (C) 2021 Bicky Thapa et al. This is an open access article distributed under the Creative Commons Attribution License, which permits unrestricted use, distribution, and reproduction in any medium, provided the original work is properly cited.

Clinical relapses early after autologous stem cell transplantation portrays an inferior clinical outcome. Early relapse in this setting with extramedullary disease (EMD) of lung involvement in multiple myeloma is rare. To our knowledge, this is the first reported case of lymphangitic spread of myeloma with pulmonary parenchymal and pleural involvement occurring at first relapse.

\section{Introduction}

Multiple myeloma (MM) is characterized by malignant clonal proliferation of plasma cells and is known for relapsing disease course with a small cure fraction. Extramedullary disease (EMD) in MM exemplifies a clonally evolved population of myeloma cells that can survive independent of the bone marrow (BM) microenvironment and confers treatment resistance and adverse clinical outcome. Herein, we report a rare case of fulminant pulmonary lymphangitic relapse of myeloma with extramedullary pulmonary involvement as the first clinical presentation of relapse occurring within 90 days after an upfront autologous stem cell transplantation (ASCT).

\section{Case}

A 63-year-old female presented with R-ISS stage II IgG kappa MM after disease progression from monoclonal gammopathy of undetermined significance (MGUS). She had high-risk cytogenetics del17p (unknown clone size) on FISH with complex karyotype. She presented with back pain resulting from a thoracic vertebral paramedullary mass at T12 with no neurological compromise. ${ }^{18}$ F-FDG PET at diagnosis showed multiple focal lesions with no extramedullary disease. The patient proceeded with $30 \mathrm{~Gy}$ local radiation to thoracic spine and induction therapy with KRD for 4 cycles achieving a partial response (IMWG criteria), followed by high dose chemotherapy (HDC) and ASCT. ASCT did not further deepen the response and the patient attained partial response, hence the plan was to proceed with additional KRD consolidation followed by maintenance therapy. However, the patient presented with worsening shortness of breath (SOB) and cough approximately D +90 after ASCT requiring hospitalization. A computed tomography (CT) at admission showed new bilateral lower lobe infiltrates with consolidation and innumerous pulmonary nodules (Figure 1). She was started on broad-spectrum antibiotics for suspected bacterial pneumonia. Incidentally, she was also found to have worsening pancytopenia with an elevated lactate dehydrogenase 609 unit/L without laboratory evidence of hemolysis. Peripheral smear reported $1 \%$ circulating plasma cells by morphology. An extensive infectious workup was unrevealing. Bronchoscopy with bronchoalveolar lavage (BAL) revealed atypical plasma cells with a malignant pleural effusion. A repeat CT scan was performed for persistent hypoxia, which showed further worsening of bilateral lower lobe consolidation along with extensive ground-glass density, interlobular septal thickening, and patchy consolidation throughout the upper lobes as well as superior segments of the lower lobes (Figure 1). 


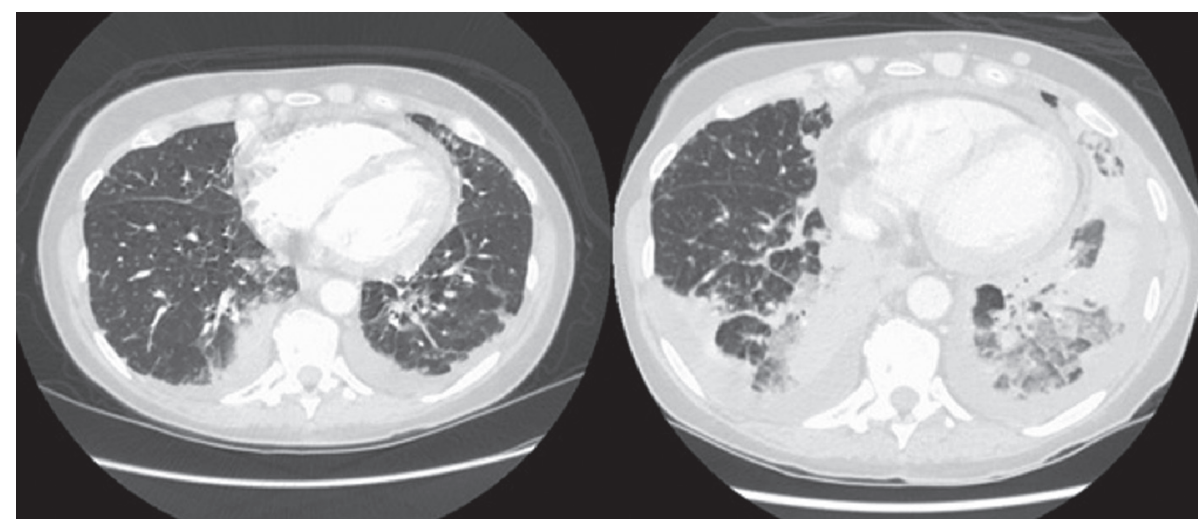

(a)
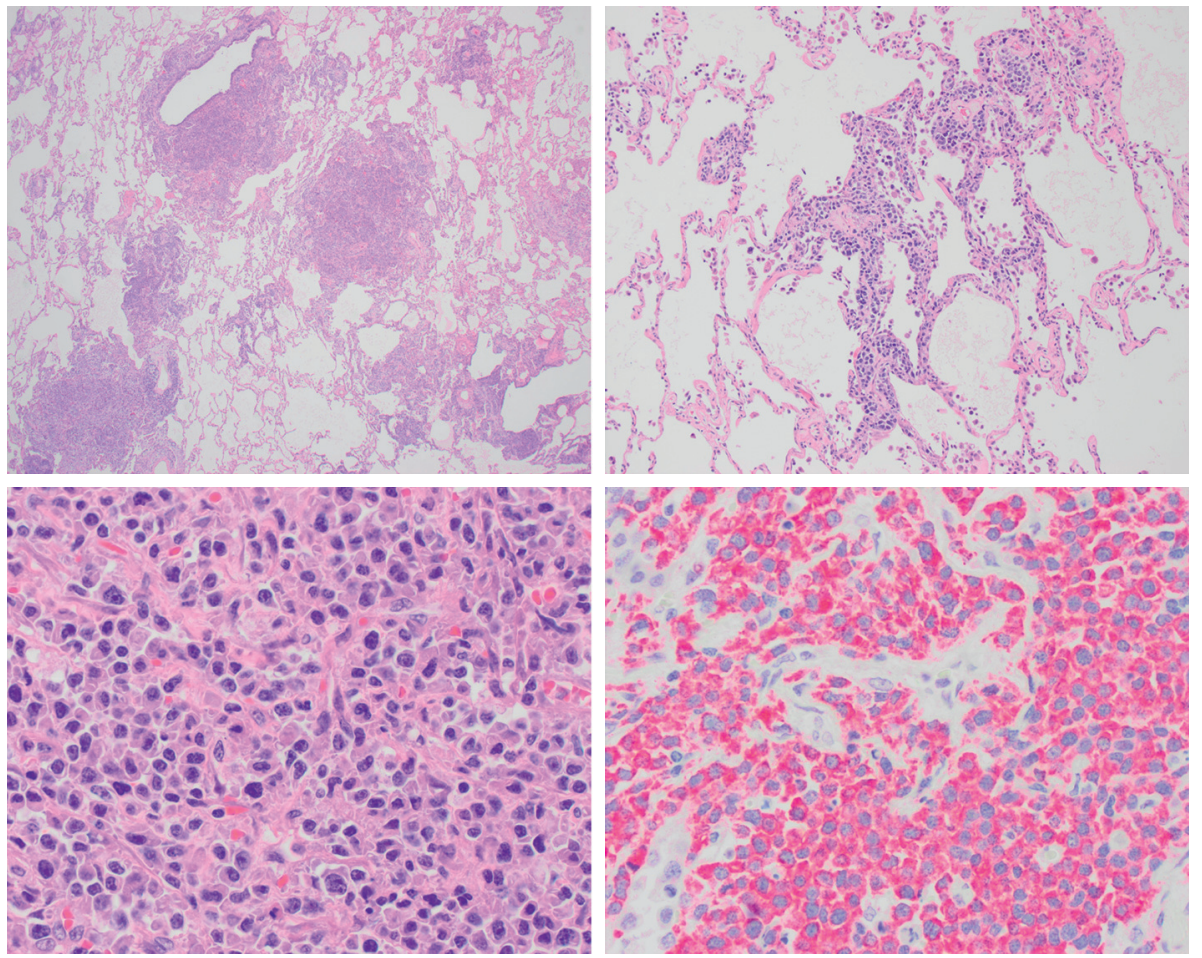

(b)

Figure 1: (a) Coronal sections of computed tomography showing worsening of bilateral lower lobe consolidation along with extensive ground-glass density, interlobular septal thickening. (b) Pathological specimen showing infiltration of lung parenchyma by kappa light chain restricted atypical plasma cells with a large, round to irregular nuclei, variably prominent nucleoli, and moderate amounts of eosinophilic cytoplasm. Flow cytometry showed $17.9 \%$ plasma cells with the following immunophenotypic markers (CD5 (-), CD10 (-), CD19 (-), CD20 (-), CD38 (bright+), CD45 (dim+), CD56 (partial dim+), CD138 (variably+), and CD319 (+)) (Hematoxylin and eosin; $20 x, 100 x, 500 x$, and $500 x$, respectively.)

Video-assisted thoracoscopy and lung biopsy showed extensive patchy involvement of lung parenchyma by clonal kappa-restricted plasma cells in perivascular, peribronchial, and periseptal distribution in addition to focally forming variably sized aggregates (Figure 1). Bone marrow (BM) biopsy was $95 \%$ cellular, with $88.9 \%$ monotypic kappa-restricted plasma cells. FISH studies on the BM aspirate showed deletion of $1 \mathrm{p}$ with a gain of 1q, a gain of FGFR3 (4p16), the gain of MYC (8q24), the gain of CCND1 (11q13), monosomy 13 , a complex $t(14 ; 16)$ IGH-MAF translocation, TP53 deletion, and gain of MAFb (20q12) observed in
$29-96 \%$ of plasma-cell-enriched cells analyzed. This is in contrast to the FISH studies at initial diagnosis which showed 1q21 gain, the gain of MYC, $t(14 ; 16)$ in addition to the original TP53 clone. Cytogenetics showed a complex tetraploid karyotype with (del)17P. Taken together, the clinical picture was consistent with a marrow relapse and extramedullary myelomatous lung involvement with lymphangitic spread and malignant pleural effusion. The patient became progressively hypoxic, requiring admission to the intensive care unit. She was started on methylprednisolone 1 gram daily for 3 days followed by bendamustine $(90 \mathrm{mg} /$ 
TABLE 1: Summary of case reports with myelomatous lung involvement and their outcomes.

\begin{tabular}{|c|c|c|c|c|c|c|c|}
\hline Case reports & $\begin{array}{l}\text { Age } \\
\text { and } \\
\text { gender }\end{array}$ & $\begin{array}{l}\text { Diagnostic } \\
\text { modality }\end{array}$ & $\begin{array}{c}\text { Subtype of } \\
\text { myeloma }\end{array}$ & Cytogenetics & $\begin{array}{l}\text { EMD involvement of } \\
\text { the lung }\end{array}$ & Treatments & Status \\
\hline $\begin{array}{l}\text { Marmor et al. } \\
{[13]}\end{array}$ & $65, \mathrm{~F}$ & Lung biopsy & IgG kappa & NA & $\begin{array}{c}\text { At initial diagnosis of } \\
\text { MM }\end{array}$ & None & Expired \\
\hline Nitu et al. [14] & $60, \mathrm{M}$ & BAL & $\operatorname{IgG}$ & NA & $\begin{array}{c}\text { At initial diagnosis of } \\
\text { MM }\end{array}$ & None & Unknown \\
\hline Yuan et al. [15] & $58, \mathrm{M}$ & BAL & IgG kappa & $\begin{array}{l}t(11 ; 14)(\mathrm{q} 13 ; \\
\mathrm{q} 32) \text { and del } \\
13 \mathrm{q} 14.3\end{array}$ & 4 years after ASCT & $\begin{array}{l}\text { Induction: vincristine, } \\
\text { adriamycin, and } \\
\text { dexamethasone (VAD) } \\
\text { followed by ASCT } \\
\text { while hospitalized: } \\
\text { thalidomide, } \\
\text { dexamethasone, } \\
\text { bortezomib, and } \\
\text { doxorubicin. }\end{array}$ & Expired \\
\hline $\begin{array}{l}\text { Kushwaha } \\
\text { et al. [18] }\end{array}$ & $60, \mathrm{M}$ & $\begin{array}{c}\text { Lung biopsy } \\
\text { and BMBx }\end{array}$ & $\operatorname{IgG}$ & NA & $\begin{array}{c}\text { At initial diagnosis of } \\
\text { MM }\end{array}$ & None & Expired \\
\hline $\begin{array}{l}\text { Sahin Balcik } \\
\text { et al. [18] }\end{array}$ & $62, \mathrm{M}$ & Lung biopsy & IgA kappa & $\begin{array}{c}\operatorname{Del}(13 q), \\
\text { hypodiploidy }\end{array}$ & $\begin{array}{l}\text { At initial diagnosis of } \\
\text { MM }\end{array}$ & $\begin{array}{l}\text { Vincristine, adriamycin, } \\
\text { dexamethasone (VAD) }\end{array}$ & Expired \\
\hline $\begin{array}{l}\text { Ravinet et al. } \\
\text { [17] }\end{array}$ & $61, \mathrm{M}$ & $\begin{array}{l}\text { Lung tissue } \\
\text { autopsy }\end{array}$ & IgG kappa & $t(4 ; 14)$ & $\begin{array}{c}6 \text { months after } \\
\text { diagnosis of MM; } \\
\text { EMD lung within } 2 \\
\text { months of ASCT }\end{array}$ & $\begin{array}{c}\text { Induction: bortezomib, } \\
\text { thalidomide, and } \\
\text { dexamethasone followed by } \\
\text { ASCT }\end{array}$ & Expired \\
\hline Lok et al. [16] & $64, \mathrm{M}$ & $\begin{array}{c}\text { Chest wall } \\
\text { mass biopsy } \\
\text { and BAL }\end{array}$ & $\begin{array}{l}\text { Lambda } \\
\text { light chain }\end{array}$ & NA & $\begin{array}{l}5 \text { months after } \\
\text { diagnosis of } \mathrm{MM}\end{array}$ & NA & Expired \\
\hline Rai et al. [19] & $55, \mathrm{~F}$ & $\begin{array}{l}\text { CT guided lung } \\
\text { biopsy, BMBx }\end{array}$ & NR & NA & $\begin{array}{c}\text { At initial diagnosis of } \\
\text { MM }\end{array}$ & NA & NR \\
\hline $\begin{array}{l}\text { Abhishek et al. } \\
{[20]}\end{array}$ & $58, \mathrm{M}$ & Lung biopsy & NR & NA & $\begin{array}{c}1 \text { year after diagnosis } \\
\text { of } \mathrm{MM}\end{array}$ & $\begin{array}{l}\text { Induction therapy: } \\
\text { bortezomib, thalidomide, } \\
\text { and dexamethasone. } \\
\text { Treatment for relapse not } \\
\text { reported. }\end{array}$ & NR \\
\hline Shah et al. [21] & $60, \mathrm{M}$ & $\begin{array}{l}\text { CT guided } \\
\text { FNAC of lung } \\
\text { mass, BMBx }\end{array}$ & $\operatorname{IgG}$ & NA & $\begin{array}{l}\text { At initial diagnosis of } \\
\text { MM }\end{array}$ & Melphalan, prednisone & Unknown \\
\hline $\begin{array}{l}\text { Furuncuoglu } \\
\text { et al. [22] }\end{array}$ & $42, \mathrm{M}$ & $\begin{array}{l}\text { CT guided } \\
\text { lung biopsy }\end{array}$ & $\begin{array}{l}\text { Lambda } \\
\text { light chain }\end{array}$ & NA & $\begin{array}{c}\text { At initial diagnosis of } \\
\text { MM }\end{array}$ & NA & Unknown \\
\hline
\end{tabular}

NA, not available; NR, not reported; BAL, bronchoalveolar lavage; BMBx, bone marrow biopsy; ASCT, autologous stem cell transplant; CT, computed tomography; EMD, extramedullary disease.

$\left.\mathrm{m}^{2}\right) \times 2$ days. Unfortunately, the MM was proved difficult to control, thus we proceeded with salvage KPACE with minimal symptomatic improvement. Given the incurable nature of disease and limited prognosis, the patient opted for hospice care.

\section{Discussion}

The incidence of EMD in MM had increased from 6.5\% in 2005 to $23.7 \%$ in 2014 based on a recent registry study, and this is ascribed to the improving survival of MM patients and routine integration of novel imaging techniques such as PET CT and MRI DWIBS in clinical practice [1]. It has been postulated that repeated relapse after exposure to novel agents promote a clonal evolution and establishment of more aggressive clones, which account for an increase in
EMD, but this theory had been refuted by more recent studies [2]. As expected, EMD is more frequent in the relapsed refractory setting with distribution showing mostly a predominance of liver involvement in the posttransplant setting compared to more skin and soft tissue at diagnosis [3]. EMD in general portends poor prognosis due to the aggressive nature of the disease and resistance to chemotherapy. While EMD is rare at the initial diagnosis, it confers an inferior 5-year progression free survival (PFS) of $21 \%$ overall survival (OS) of $31 \%^{3}$.

EMD correlates with a high-risk 70-gene expression profiling signature with enrichment of MF molecular subgroup and the PR molecular subgroup [3]. In addition, EMD at the time of diagnosis is a robust predictor of EMD in the relapse setting [4]. It had been postulated that EMD develops because of a "bone marrow escape" of more clonally evolved 
plasma cells capable of surviving independently of bone marrow microenvironment akin to primary plasma cell leukemia (pCL). Indeed, whole-exome sequencing and gene expression profiling analysis of PCL showed enrichment for high-risk mutations in addition to downregulation of adhesion molecules present in the extracellular matrix supporting their extramedullary survival $[5,6]$. TP53 deletions and MYC overexpression by FISH were shown to be presented in a significant proportion of patients presenting with EMD like our patient driving a state of increased proliferation and decreased apoptosis analogous to double-hit lymphoma. Furthermore, discordance in the cytogenetic markers between the bone marrow and EMD has also been observed in keeping with the clonal evolution of these populations [7, 8]. Cytogenetic or FISH analyses were not performed in the lung EMD in our patient, and the genetics is unknown. Concomitant secondary central nervous system involvement has a distinctive association with EMD and spinal fluid examination in our patient was unremarkable.

Our case is unique due to the clinical presentation of early fulminant relapse within 90 days of ASCT with lymphangitic and parenchymal involvement of the lung along with the pleura. The relapse pattern could be due to a hematogenous inoculum of plasma cells in the lung followed by perivascular lymphatic spread into pulmonary parenchyma. In addition, early relapse within the first 24 months of ASCT occurring in 35-38\% of newly diagnosed multiple myeloma (NDMM) confers an inferior clinical outcome [9]. More recently, a study reported a unique subset (12.9\%) of NDMM relapsing within 12 months of ASCT. Cytogenetics defined high risk and ultra-high risk was significantly greater in this subset of patients with a progression free survival of 18 months and overall survival of 26 months, once again underscoring the dismal outcome in this subset of patients $[10,11]$.

Our case highlights the very aggressive nature of the disease depicted by the presence of high-risk cytogenetics of (del)17p at initial diagnosis, suboptimal response to induction therapy, early relapse within 3 months of ASCT with additional high-risk cytogenetics including 1q21, and complex tetraploid karyotype with poor response to salvage therapy. Interestingly, in our case, there is a striking discordance in the flow cytometry expression of CD56 or neural cell adhesion molecule (NCAM) with BM being negative and extramedullary lung site positive perhaps suggesting a clonal evolution [12]. Published case reports of EMD with lung involvement demonstrated high mortality with dismal prognosis [13-17] (Table 1). So far, 11 cases have been published in the last 15 years with pulmonary parenchymal EMD. Majority of these described cases presented with lung EMD at the time of diagnosis while only two cases had lung EMD after ASCT (one within 2 months of ASCT and the other 4 years after ASCT). Overall clinical outcome has been dismal (Table 1). Clinical presentation is variable and a high index of suspicion is crucial [13-17, 23]. Besides, our patient was perplexing with COVID-19-related pneumonia high on the differential. Due to rarity and underrepresentation in clinical trials, there is no consensus on the optimal management of these subsets of patients; we opted for salvage multiagent chemotherapy in combination with novel agents. Long-term favorable outcomes have been described following alloSCT [24], which option our patient declined to pursue. Indeed, the expression of CD 38 is preserved in the $\mathrm{BM}$ and EMD possibly implying the role of novel CD 38 targeting antibodies, bispecific T-cell engager (BiTE), and chimeric antigen receptor (CAR) T-cell therapy. Extramedullary involvement of lung parenchyma with a lymphangitic spread as the first evidence of an early relapse after an upfront ASCT is extremely rare and associated with poor outcomes.

\section{Abbreviations \\ KRD: $\quad$ Kyprolis (carfilzomib), Revlimid (lenalidomide), and low-dose dexamethasone \\ KPACE: Kyprolis (carfilzomib) $20 \mathrm{mg} \cdot \mathrm{m}^{2} \mathrm{D} 1,2$ and $36 \mathrm{mg} /$ $\mathrm{m}^{2} \mathrm{D} 8$, 9, cisplatin $10 \mathrm{mg} / \mathrm{m}^{2} \mathrm{D} 1-4$, adriamycin $10 \mathrm{mg} / \mathrm{m}^{2}$ D1-4, cyclophosphamide $400 \mathrm{mg} / \mathrm{m}^{2}$ D1-4, and etoposide $40 \mathrm{mg} / \mathrm{m}^{2} \mathrm{D} 1-4^{18} \mathrm{~F}$-FDG \\ PET: $\quad{ }^{18} \mathrm{~F}$-2-Fluoro-2-deoxyglucose positron emission tomography/computed tomography \\ FISH: $\quad$ Fluorescence in situ hybridization \\ MRI Diffusion-weighted whole-body imaging with \\ DWIBS: background body signal suppression \\ IMWG: International myeloma working group.}

\section{Conflicts of Interest}

The authors declare that they have no conflicts of interest.

\section{Authors' Contributions}

Bicky Thapa and Gulrayz Ahmed are co-first authors and contributed equally to this article.

\section{References}

[1] N. Gagelmann, D.-J. Eikema, S. Iacobelli et al., "Impact of extramedullary disease in patients with newly diagnosed multiple myeloma undergoing autologous stem cell transplantation: a study from the chronic malignancies working party of the EBMT," Haematologica, vol. 103, no. 5, pp. 890-897, 2018.

[2] C. Varga, W. Xie, J. Laubach et al., "Development of extramedullary myeloma in the era of novel agents: no evidence of increased risk with lenalidomide-bortezomib combinations," British Journal of Haematology, vol. 169, no. 6, 2015.

[3] S. Z. Usmani, C. Heuck, A. Mitchell et al., "Extramedullary disease portends poor prognosis in multiple myeloma and is over-represented in high-risk disease even in the era of novel agents," Haematologica, vol. 97, no. 11, pp. 1761-1767, 2012.

[4] C. Varga, W. Xie, J. Laubach et al., "Development of extramedullary myeloma in the era of novel agents: no evidence of increased risk with lenalidomide-bortezomib combinations," British Journal of Haematology, vol. 169, no. 6, pp. 843-850, 2015.

[5] C. Schinke, E. M. Boyle, C. Ashby et al., "Genomic analysis of primary plasma cell leukemia reveals complex structural alterations and high-risk mutational patterns," Blood Cancer Journal, vol. 10, no. 6, pp. 1-9, 2020. 
[6] C. J. Neuse, O. C. Lomas, C. Schliemann et al., "Genome instability in multiple myeloma," Leukemia, vol. 34 , no. 11 , p. 2887,2020 .

[7] L. Billecke, E. M. Murga Penas, A. M. May et al., "Cytogenetics of extramedullary manifestations in multiple myeloma," British Journal of Haematology, vol. 161, no. 1, pp. 87-94, 2013.

[8] L. Rasche, C. Bernard, M. S. Topp et al., "Features of extramedullary myeloma relapse: high proliferation, minimal marrow involvement, adverse cytogenetics: a retrospective single-center study of 24 cases," Annals of Hematology, vol. 91, no. 7, pp. 1031-1037, 2012.

[9] S. K. Kumar, A. Dispenzieri, R. Fraser et al., "Early relapse after autologous hematopoietic cell transplantation remains a poor prognostic factor in multiple myeloma but outcomes have improved over time," Leukemia, vol. 32, no. 4, pp. 986-995, 2018.

[10] C. Bygrave, C. Pawlyn, F. Davies et al., "Early relapse after high-dose melphalan autologous stem cell transplant predicts inferior survival and is associated with high disease burden and genetically high-risk disease in multiple myeloma," British Journal of Haematology, 2020.

[11] B. A. Walker, K. Mavrommatis, C. P. Wardell et al., "A highrisk, double-hit, group of newly diagnosed myeloma identified by genomic analysis," Leukemia, vol. 33, no. 1, pp. 159-170, 2019.

[12] A. M. Harrington, P. Hari, and S. H. Kroft, "Utility of CD56 immunohistochemical studies in follow-up of plasma cell myeloma," American Journal of Clinical Pathology, vol. 132, no. 1, pp. 60-66, 2009.

[13] D. B. Marmor, J. L. Farber, and J. E. Gottlieb, "Acute respiratory distress syndrome due to pulmonary involvement by neoplastic plasma cells in multiple myeloma," Thorax, vol. 61, no. 5, pp. 455-456, 2006.

[14] M. Niţu, E. Crișan, M. Olteanu, C. Călăraşu, M. Olteanu, and M. R. Popescu, "Lung involvement in multiple myeloma-case study," Current Health Sciences Journal, vol. 40, no. 4, pp. 274-276, 2014.

[15] Y. Yuan, R. Wieczorek, D. L. Green, P. Cook, H. Ballard, and D. J. Araten, "Multiple myeloma involving skin and pulmonary parenchyma after autologous stem cell transplantation," Journal of Hematology \& Oncology, vol. 2, no. 1, p. 48, 2009.

[16] R. Lok, D. Golovyan, and J. Smith, "Multiple myeloma causing interstitial pulmonary infiltrates and soft-tissue plasmacytoma," Respiratory Medicine Case Reports, vol. 24, pp. 155157, 2018.

[17] A. Ravinet, S. Perbet, R. Guièze et al., "Lung postmortem autopsy revealing extramedullary involvement in multiple myeloma causing acute respiratory distress syndrome," Case Reports in Hematology, vol. 2014, Article ID 635237, 2014.

[18] O. Sahin Balcik, M. Albayrak, S. Dagdas et al., "A rare extramedullary involvement in myeloma: lung parenchyma and association with unfavorable chromosomal abnormalities," Turkish Journal of Hematology, vol. 27, no. 2, pp. 109-112, 2010.

[19] S. Rai, H. B. Sridevi, V. Acharya, F. Lobo, and J. Kini, "Pulmonary plasmacytoma in multiple myeloma: a rare case of extramedullary spread," Egyptian Journal of Bronchology, vol. 9, no. 3, p. 293, 2015.

[20] K. Abhishek, M. Ejazi, Z. Hashim, R. Chaudhary, and K. Niharika, "Multiple myeloma with different thoracic manifestations: case series," Indian Journal of Respiratory Care, vol. 7, no. 2, p. 108, 2018.
[21] K. Saha, N. K. Sit, A. Maji, and D. Jash, "A case of multiple myeloma with lung involvement," Middle East Journal of Cancer, vol. 3, no. 2-3, pp. 75-78, 2012.

[22] Y. Furuncuoglu, "Multiple myeloma mimicking metastatic lung cancer," Turkish Journal of Oncology, vol. 30, no. 3, 2015.

[23] R. S. Kushwaha, S. Kumar, S. Mehra, and R. Prasad, "Pulmonary and nodal multiple myeloma with a pleural effusion mimicking bronchogenic carcinoma," Journal of Cancer Research and Therapeutics, vol. 5, no. 4, pp. 297-299, 2009.

[24] M. C. Minnema, N. W. C. J. Van De Donk, S. Zweegman et al., "Extramedullary relapses after allogeneic non-myeloablative stem cell transplantation in multiple myeloma patients do not negatively affect treatment outcome," Bone Marrow Transplantation, vol. 41, no. 9, pp. 779-784, 2008. 